\title{
Mapping the Health, Safety and Wellbeing Challenges of Firefighting to Wearable Devices
}

\author{
Michael Devine \\ Ulster University \\ School of Health Science \\ devine-m13@ulster.ac.uk
}

\author{
Raymond Bond \\ Ulster University \\ School of Computing \\ rb.bond@ulster.ac.uk
}

\author{
Victoria Simms \\ Ulster University \\ School of Psychology \\ v.simms@ulster.ac.uk
}

\author{
Karen Boyce \\ Ulster University \\ Belfast School of Architecture and the Built Environment \\ ke.boyce@ulster.ac.uk
}

\author{
Daniel Kerr \\ Ulster University \\ School of Health Sciences \\ dp.kerr@ulster.ac.uk
}

\begin{abstract}
Firefighting remains a dangerous job and those employed face many challenges to health, safety and wellbeing. The risks faced range from immediate threat to life and limb to long term, repeated exposure to hazardous environments and arduous working conditions. Many of these hazards can be mitigated by recording exposure to risks, processing risk data, improving information flow and increasing situational awareness. Cyber-physical systems and interactive smart wearables offer a smart and seamless suite of tools that can help achieve these goals and allow emergency responders to work more efficiently and safely. Here we examine how data from wearable devices can be used to improve health, safety and wellbeing of the firefighter.
\end{abstract}

\section{Smart Firefighting, Biometrics, Human-Data Interaction.}

\section{INTRODUCTION}

Levels of ill health are above average in the UK Fire and Rescue Services (UKFRS) and there is a high incidence of on-duty firefighter death. 122 deaths occurred between 1978 and 2008 (The Fire Brigades Union, 2008) and detailed analysis of firefighter deaths and injuries between 2004-2013 stated that the current "scale of death and injury is unacceptable" (Watterson, 2014).

Traditional efforts to improve safety have been reactive to adverse events and often involve changes in working practices. Today, firefighters work in a sensor-rich environment with few opportunities to access the data produced. Smart firefighting sees the fusion of these new technologies with traditional firefighting practices. These emerging cyber-physical systems will transform emergency response and firefighting (Hamins, 2014).
Smart firefighting involves integration of data from a range of sources (Grant, 2015):

(i) Environmental: Infrastructure and community data systems, building systems.

(ii) Operational: Firefighting apparatus and equipment.

(iii) Personal: Firefighter personal protective equipment (PPE) and electronic safety equipment (ESE).

Here we examine how personal wearable sensors and biometrics may be used to make firefighters more effective and efficient and improve occupational health, safety and wellbeing.

\section{WEARABLE COMPUTING FOR FIREFIGHTER HEALTH, SAFETY AND WELLBEING}

Firefighters work in an environment that can place considerable strain on the body. Carrying out strenuous activities in heavy protective clothing in 
high environmental heat can compound this stress (Barr, 2010). They are already overburdened with equipment; wearable sensor solutions may provide ways to mitigate specific hazards associated with the working environment and imposed stressors. In the following sections, we provide an overview of how wearable computing can 1) help make sense of the thermal environment, 2) monitor the physiology or psychophysiology/cognition of the firefighter, and 3) provide feedback to maintain health and wellbeing. The target variables to specific health challenges are summarised in table 1.

\subsection{Making sense of the thermal environment}

Wearable instrument packages were first used to gather data on the thermal environment encountered by firefighters under controlled live fire conditions with the aim of developing sufficient standards for equipment, clothing and safe systems of work. Early investigations concentrated on characterising the bearable, safe limits for firefighter training using devices that were deemed to be impractical for operational use (Foster, 1994).

A recent series of fatalities during live-fire training in the United States has prompted further investigation of typical thermal exposures using a wearable measurement and data acquisition system integrated into firefighter's PPE. The study showed that the heat flux experienced by the wearer was often higher than ambient temperatures measured at fixed points in the training facilities (Willi, 2016).

These studies have gathered valuable data to improve firefighter safety during training but there has been no attempt to use this technology in the operational environment. The benefits of such sensemaking technology are clear; the investigation into the deaths of firefighters James Shears and Alan Bannon in Hampshire recommended that consideration be given to providing a method of identifying hazardous temperatures (Hampshire Fire and Rescue Service, 2013).

Hand-held thermal imaging technology may help mitigate this risk. The firefighter can use these cameras to actively scan the area for hazards, but this means they must make sense of the acquired imagery while simultaneously coping with firefighting tasks, communicating with team mates and searching for survivors. An alternative, wearable solution might involve sensors embedded in the PPE that could monitor radiant heat or increases in temperature associated with rapid fire development and warn the wearer simple with audible, visual or haptic cues, freeing up the wearer to concentrate on the relevant executive tasks.

\subsection{Real time physiological monitoring}

The thermal environment encountered by firefighters can pose considerable strain on the body and this is compounded by performing strenuous tasks associated with the job. The physiological impact of carrying out firefighting tasks has been studied in experimental settings. Common consequences include increases in heart rate, skin temperature, core temperature, perceived exertion, cardiac stroke volume, and sweat rate (Barr, 2010).

Near maximal heart rates have been recorded during simulated fire suppression activities (Smith, 1996) and even brief bouts of firefighting activity can result in moderate to high levels of heat strain (Petruzzello, 2009). The same strenuous fire suppression activities have been associated with more than $30 \%$ of on-duty sudden cardiac deaths observed in data from the United States (Kales, 2014). Similarly, 36 deaths recorded in the UKFRS workforce between 1978-2008 "attributed to natural causes were generally heart attacks, which took place either at incidents or shortly afterwards" (The Fire Brigades Union, 2008).

Fire incident commanders are trained to manage the health hazards associated with heat strain and exertion in hot environments by implementing practical measures including rest breaks after heat exposure, accelerated cooling, rehydration and rotation of personnel to limit exposure (Fire and Rescue Authority, 2014). However, the investigation into recent firefighter fatalities in the UK noted many recurring contributory factors and there was concern that advice on managing heat stress was being ignored (Watterson, 2014).

A Coroner's Rule 28 Report on a firefighter fatality in 2013 recommended that UK Fire and Rescue Services implement measures to reduce the risks associated with the physiological effects of working in a hot environment. This included development of training and guidance for firefighters to recognise the physiological effects of heat on themselves and their colleagues and to know when to withdraw from danger (Meadows, 2016). But how does one recognise the onset of heat strain when symptoms include a decline in cognitive function (Schmit, 2017)?

Current safety measures are limited and include distress signal units that can be activated manually when in need of help or automatically when they no longer register movement of the wearer. The unit then produces an audible alarm and in some cases a radio distress signal. However, evidence from the 
investigation into the death of firefighter Ewan Williamson in 2009 suggests that firefighters under extreme stress may be reluctant or unable to activate their distress signal units.

The investigation identified that firefighter Williamson did not activate his distress signal unit even though he was instructed to do so when he requested assistance by radio after becoming lost and trapped in the burning building. No distress signal was heard until 45 minutes after the radio message (Scottish Fire and Rescue Service, 2016). Similarly, the Coroner's Investigation in to the death of firefighter Stephen Hunt revealed that he and his team mate encountered extremely hot conditions and suffered cognitive effects from this exposure; even when he realised they were in danger, Stephen's team mate was unable to manually operate his distress signal unit (Meadows, 2016).

It is vitally important to know when a firefighter is in danger or has become immobilised but it would be safer and more useful to identify signs of psychophysiological strain well before conditions worsen to the point where performance and competence collapse: Removing an unconscious and immobile firefighter from danger is a difficult and hazardous task.

A range of PPE embedded sensors could provide more relevant, useful measures of the firefighter's health and wellbeing. Heart rate data would provide an obvious indicator of heart health and recent research shows that it can be give an accurate estimation of real-time core body temperature (Buller, 2015). This could be combined with other data such as galvanic skin response and breathing rate to assess overall emotional state (Dupré, 2018). This would allow real-time monitoring of wearer health and wellbeing, alerting the wearer and their colleagues of potential issues before their condition deteriorates to a dangerous state. In addition, fatigue could be assessed so that personnel receive adequate rest after strenuous activities and are rotated back in to duty at an appropriate time and with appropriate duties.

\subsection{Maintenance of health, fitness and wellbeing}

The immediate health risks associated with firefighting are clear but chronic exposure may also pose health problems. A growing body of evidence suggests that occupational exposure to carcinogens associated with combustion products may contribute to an increased incidence of a range cancers in firefighters (Daniels, 2015). Biomarkers for these combustion products have been detected in firefighters even when wearing full protective equipment, suggesting that carcinogens may be absorbed through the skin or breathed in from contaminated equipment after the fire (Fent, 2017).

Fire service instructors, who frequently train and teach in hot environments, and face repeated exposure to physiological and perceptual heat strain report symptoms of ill health like those seen in overtrained athletes. Key themes include fatigue, headaches, broken sleep and heart palpitations (Watkins, 2017). Firefighters' physiological and psychological responses to heat exposure also indicate that they may be experiencing symptoms and changes to their health consistent with an over training type condition (Watt, 2016).

A means of monitoring exposure to stressors such as heat and combustion products could allow more effective management and mitigation of risk through simple interventions such as rotation of personnel. A personalised approach could use a smart phonebased tracker to log exposure details, such as the types of incidents attended, and activities performed. This could provide alerts or advice relevant to health and wellbeing (Savacool, 2015).

Maintaining an appropriate level of fitness and body composition may mitigate the immune and inflammatory responses associated with these types of exposure (Walker, 2017) while also improving performance and safety across a variety of firefighting tasks (Barr, 2010). UK fire and rescue services currently provide guidance to help their employees maintain fitness, health and well-being, and for employers to provide occupational fitness support to firefighters throughout their career (Firefighter Fitness Joint Working Group, 2016). A minimum fitness standard throughout active service $\left(\mathrm{VO}_{2}\right.$ max of $\left.42 \mathrm{ml} \mathrm{kg}^{-1} \mathrm{I}^{-1}\right)$ is generally accepted but this is increasingly difficult to maintain with age, especially for women (Williams, 2014)

Evidence suggests that firefighters may have problems maintaining healthy lifestyle practices. A large, cross-sectional study of UK firefighters identified that levels of habitual exercise tended to decrease with age and that this could have negative implications on weight management and cardiovascular disease risk over the course of a career. In addition, there was evidence of poor and disrupted sleep that could influence psychosocial health and wellbeing. The investigators recommended that health and fitness advice to firefighters should include strategies to promote a healthy lifestyle to maintain safe and effective levels of fitness throughout their careers (Siddall, 2014). 
Wearable fitness devices and fitness apps are becoming increasingly popular and have the potential to improve health by promoting behavioural change. Common features used by these devices, such as activity monitoring, diet tracking, and sleep quality analysis could be employed to track and help educate and empower firefighters to make healthy lifestyle decisions. However, the huge range of available devices, the various methods of measurement and differing strategies for informing the user means that no single suite of features can be shown to be most effective. A recent review stated that the most helpful strategies for increasing activity and healthy behaviours include goal setting, self-monitoring, feedback, rewards, social support, and coaching (Sullivan, 2017). Perhaps these strategies can be incorporated by UK Fire and Rescue Services to help encourage healthy behaviours so that their "firefighters are not just fit to fight fires, they are largely free of the chronic diseases that bedevil the remainder of the population" (Williams, 2014).

Table 1: Summary of target variables to firefighter health challenges

\begin{tabular}{|l|l|l|}
\hline $\begin{array}{l}\text { Wearable } \\
\text { sensors }\end{array}$ & Target variable & $\begin{array}{l}\text { Health } \\
\text { challenge }\end{array}$ \\
\hline $\begin{array}{l}\text { Heat flux } \\
\text { microsensor }\end{array}$ & Radiant heat & $\begin{array}{l}\text { Thermal } \\
\text { exposure }\end{array}$ \\
\hline $\begin{array}{l}\text { Optical / } \\
\text { electrical heart } \\
\text { rate sensor }\end{array}$ & $\begin{array}{l}\text { Heart rate } \\
\text { Core } \\
\text { temperature } \\
\text { Daily activity } \\
\text { levels }\end{array}$ & $\begin{array}{l}\text { Heat strain } \\
\text { and fatigue } \\
\text { Health and } \\
\text { fitness }\end{array}$ \\
\hline Accelerometer & $\begin{array}{l}\text { Fall detection } \\
\text { Physical activity } \\
\text { Rate of motion } \\
\text { Sleep quality and } \\
\text { duration }\end{array}$ & $\begin{array}{l}\text { Heat strain } \\
\text { and fatigue } \\
\text { fitness }\end{array}$ \\
\hline $\begin{array}{l}\text { Galvanic skin } \\
\text { response }\end{array}$ & $\begin{array}{l}\text { Stress, } \\
\text { psychosocial } \\
\text { health }\end{array}$ & $\begin{array}{l}\text { Heat strain } \\
\text { and fatigue }\end{array}$ \\
\hline
\end{tabular}

\section{Conclusion}

Firefighters face challenges to health, safety and wellbeing throughout their careers. Wearable instrument packages have been used to great effect to study the physiological impacts associated with carrying out strenuous activities in conditions of high environmental heat and wearing heavy protective equipment. This valuable data may help mitigate the hazards faced by improving equipment and working practices.

However, fatal fire investigations show that firefighters face recurrent issues associated with the psychophysiological strain associated with working in high temperatures and there is now a need to better understand the link between the stresses faced and their potential impact on decision making and physical competence. Efforts to monitor and mitigate the potential impacts of this stress could be improved by employing wearable devices. Further studies could assess the viability of using emerging sensor technologies to help identify markers of psychophysiological strain that could forewarn of a deterioration of performance and competence in the working environment. This would greatly improve safety and decision making on the incident ground.

Research is needed to examine feasibility and to determine which technologies can provide reliable, valid data, and deliver it to the user in a meaningful way. Any device for use in the operational environment would need to be robust yet unobtrusive with a simple user interface that does not impinge on the firefighter's ability to concentrate on the tasks at hand. Indeed, it would be useful to determine exactly what sources of information are used by the firefighter to make sense of their environment so that any intuitive or learned skills could be enhanced. Using technologies that are proven and readily available in a wide range of wearable devices might be a more effective and economically viable option to promote change than investing in novel, high risk solutions.

Evidence suggests that repeated exposure to stressors associated with firefighting activities can have an impact on long term health and this may help explain the higher than average levels of ill health observed in UK Fire and Rescue Services. Consumer wearable devices and apps may offer a variety of ways to mitigate the impacts by allowing the firefighter to monitor and maintain health, fitness and wellbeing.

Providing relevant data and advice could help firefighters make informed decisions and promote healthy behavioural change to reduce ill health and maintain performance and physical competence with age. Further research could help identify the most effective targets for intervention. This could offer an appealing opportunity for the employer to encourage healthy practices in the workforce that might help improve performance and reduce ill health and injury. 


\section{REFERENCES}

Barr, D. (2010) The thermal ergonomics of firefighting reviewed. Applied Ergonomics, 41, 161-172.

Buller, M. (2015) Real-time core body temperature estimation from heart rate for first responders wearing different levels of personal protective equipment. Ergonomics, 58, 1830-1841.

Daniels, R. (2013) Exposure-response relationships for select cancer and non-cancer health outcomes in a cohort of US firefighters from San Francisco, Chicago and Philadelphia (1950 - 2009). Occupational and Environmental Medicine, 72, 699-706.

Dupré, D. (2018) Dynamic Model of Athletes' Emotions Based on Wearable Devices. International Conference on Applied Human Factors and Ergonomics, Los Angeles, 17 July 2017, 42-50. Springer, Cham.

Fent, K. (2017) Contamination of firefighter personal protective equipment and skin and the effectiveness of decontamination procedures. Journal of Occupational and Environmental Hygiene, 14, 801-814.

Fire and Rescue Authority. (2014) Operational Guidance - Breathing Apparatus. The Stationary Office, Norwich.

Firefighter Fitness Joint Working Group. (2016) Firefighter fitness best practice guide. Home Office: National Joint Council for Local Authority Fire and Rescue Services.

Foster, J. (1994) Measurements of the Firefighting Environment. ODPM Publications, Wetherby, UK.

Grant, C. (2015) Realizing the Vision of Smart Fire Fighting. IEEE Potentials, 34, 35-40.

Hamins, A. (2014) Smart Firefighting Workshop Summary Report. NIST, Arlington, Virginia.

Hampshire Fire and Rescue Service. (2013) Fatal Fire Investigation: Report of the Hampshire Fire and Rescue Service investigation into the deaths of Firefighters Alan Bannon and James Shears in Flat 72, Shirley Towers, Church Street, Southampton, SO15 5PE, on Tuesday 6 April 2010. Hampshire Fire and Rescue Service.

Kales, S. (2014) Sudden cardiac death in the fire service. Occupational Medicine, 64, 228-230.

Meadows, N. (2016) Stephen Alan Hunt Regulation 28. Report to prevent future deaths. Office of the Chief Coroner.

Petruzzello, S. 2009) Perceptual and physiological heat strain: Examination in firefighters in laboratory- and field-based studies. Ergonomics, $52,747-754$.

Savacool, C. (2015) Exposure Tracking App Aims to Help Prevent Chronic Firefighter Illnesses. http://www.fireapparatusmagazine.com/articles/p rint/volume-20/issue-10/departments/tooltech/exposure-tracking-app-aims-to-helpprevent-chronic-firefighter-illnesses.html. Retrieved 13 April 2018.

Schmit, C. (2017) Cognitive Functioning and Heat Strain: Performance Responses and Protective Strategies. Sports Medicine, 47, 1289-1302.

Scottish Fire and Rescue Service. (2016) Lessons Identified Report from the Balmoral Bar Incident, Dalry Road, Edinburgh 12 July 2009. Scottish Fire and Rescue Service.

Siddall, A. (2014) Lifestyle behaviours, well-being and chronic disease biomarkers in UK operational firefighters. 61st Annual Meeting of American College of Sports Medicine, Florida, 27 May 2014, Florida.

Smith, D. (1996) Physiological, psychophysical, and psychological responses of firefighters to firefighting training drills. Aviation Space and Environmental Medicine, 67, 1063-1068

Sullivan, A. (2017) Behavior Change with Fitness Technology in Sedentary Adults: A Review of the Evidence for Increasing Physical Activity. Frontiers in Public Health, 4, 289.

The Fire Brigades Union. (2008) In the line of duty. Firefighter deaths in the UK since 1978. The Fire Brigades Union, Bradley House, 68 Coombe Road, Kingston Upon Thames, Surrey. KT2 7AE

Walker, A. (2017) Improving Body Composition May Reduce the Immune and Inflammatory Responses of Firefighters Working in the Heat. Journal of Occupational and Environmental Medicine, 59, 377-383.

Watkins, E. (2018) Fire service instructors' working practices: A UK Survey. Archives of Environmental \& Occupational Health, 73, 1-28.

Watt, P. (2016) Physiological and psychological responses in Fire Instructors to heat exposures. Journal of Thermal Biology, 58, 106-114.

Watterson, A. (2014) Firefighter fatalities at fires in the UK: 2004-2013: Voices from the fireground.. Occupational and Environmental Health Research Group, University of Stirling, Scotland.

Williams, A. (2014) Fire service pensions review. Occupational medicine, 64, 230-232. 